\title{
ON THE INTEGRATED VELOCITY EQUATIONS OF CHEMICAL REACTIONS.
}

By J. P. Dalton.

(From University College, Johannesburg.)

\section{§1. A Certain Function and its Derivatives.}

The object of this note is to show how the integrals of many velocity equations which occur in practice may be written down in terms of a certain function of the relative initial concentrations of the reactants, and of its derivatives. The function in question is

$$
\begin{gathered}
\psi \psi(x)=\frac{1}{x-1} \log _{\mathrm{e}} \frac{1-\frac{\lambda}{x}}{1-\lambda} \\
\text { where } \lambda \text { is a parameter whose significance will shortly appear. } \\
\text { Successive derivatives of } \psi \text { according to } x \text { are given by the scheme } \\
(x-1) \psi^{r}(x)+r \psi^{r-1}(x)=(-1)^{-1} \overline{r-1} !\left[\frac{1}{(x-\lambda)^{r}}-\frac{1}{x^{r}}\right]
\end{gathered}
$$

The function and its derivatives become indeterminate at $x=1$, but definite limits exist as $x \longrightarrow 1$; for these limits we find

$$
\psi(1) \rightarrow\left[\frac{1}{1-\lambda}-1\right] . \quad . \quad . \quad .
$$

and, in general,

$$
\psi^{r-1}(1)-(-1)^{r-1} \frac{\overline{r-1} !}{r}\left[(1-\lambda)^{-r}-1\right] .
$$

$\psi, \psi^{\prime}$ and $\psi^{\prime \prime}$ are tabulated in $\S 5$ for values of $\lambda$ from 0.1 to 0.9 , and for certain values of $x$ over the range 1-10.

\section{$\S 2$. The Occurrence of the Function $\psi$.}

The velocity equation of a chemical reaction is a differential equation of the type

$$
\frac{d x}{d t}=k(a-x)^{\alpha}(b-x)^{\beta}(c-x)^{\gamma} \ldots . \quad . \quad .
$$

where $a, b, \ldots$ are the initial molecular concentrations of the reactants ; $\alpha$, 
$\beta, \ldots$ the numbers of molecules of each which take part in the reaction; $x$ is the molecular amount transformed in time $t$, and $k$ is the velocity constant of the reaction.

When investigating the influence of relative initial concentration on the course of a reaction, or when comparing the velocities of different reactions, it is advantageous to work in terms of a "modular time" - that is, the time which elapses before a specified fraction, $\lambda$, of the total transformation has taken place.*

Of the initial concentrations concerned, there must be at least one which is not greater than any of the others. Let one such be $a$. The reaction will be complete when $x=a$. Refer all concentrations to $a$ as unit, and write $x=\lambda \alpha$ so that $\lambda$ is the fraction transformed at any stage; and, for the ratios $b / a, c / a, \ldots$ write $n_{1}, n_{2}, \ldots$ Equation (5) then becomes in modular form

$$
\frac{d^{\lambda}}{d \vartheta}=k a^{\alpha-1+\beta+\gamma+\cdots}(1-\lambda)^{\alpha}\left(n_{1}-\lambda\right)^{\beta}\left(n_{2}-\lambda\right)^{\gamma} \ldots
$$

The integration of equation (6) can always be effected by elementary methods, $\uparrow$ but if the indices $\alpha, \beta, \ldots$ are greater than 3 the process becomes laborious. Indeed, the chemist apparently prefers to choose, when possible, $n_{1}, n_{2}, \ldots=1$, so as to obtain a more tractable equation. That procedure, however, has the disadvantage of obscuring the effects of the influence of the relative initial concentrations of the reactants upon the course of the reaction. It may, perhaps, be of utility to show how the integrals of some of the commoner types of reaction may be obtained immediately as special cases of a general formula.

If there are $p$ reactants in all, and if only one molecule of each reactant is concerned, equation ( 6 ) becomes

$$
\frac{d \lambda}{(1-\lambda)\left(n_{1}-\lambda\right) \ldots\left(n_{p-1}-\lambda\right)}=k \alpha^{p-1} d \vartheta
$$

where $a$ is the lowest initial concentration involved. The result of integrating (7) in the usual way may be written

Now

$$
\sum_{i=0}^{i=p-1} \operatorname{II}_{j=0}^{\log \frac{n_{i}}{n_{i}-\lambda}\left(n_{j}-n_{i}\right)}=k a^{p-1.9}
$$

$$
\sum_{i=0}^{i=p-1} \frac{1}{\prod_{j=0}^{j=p-1}\left(n_{j}-n_{i}\right)}=0
$$

* Cf. Todd, Phil. Mag. xxxv, p. 281 (1918).

† See, e.g., Todhunter, Integral Calculus, Ch. II. 
and $n_{0}$ is unity (the lowest initial concentration), hence we find

$$
\sum_{i=1}^{i=p-1} \frac{\frac{1}{n_{i}-1} \log \frac{1-\frac{\lambda}{n_{i}}}{1-\lambda}}{\prod_{j=1}^{j=p-1}\left(n_{j}-n_{i}\right)}=k \alpha^{p-1} .
$$

or, in terms of the function suggested in $\S 1$,

$$
\begin{aligned}
& \left.\qquad \sum_{i=1}^{i=p-1} \prod_{j=1}^{j=p-1} \downarrow\left(n_{i}\right)=k a^{p-1 \vartheta} \cdot n_{i}-n_{i}\right) \\
& \text { So that, for instance, the integrated equation for a quadri-molecular reaction } \\
& \text { in which one molecule of each reactant takes part, becomes } \\
& \frac{\psi\left(n_{1}\right)}{\left(n_{2}-n_{1}\right)\left(n_{3}-n_{1}\right)}+\frac{\psi\left(n_{2}\right)}{\left(n_{1}-n_{2}\right)\left(n_{3}-n_{2}\right)}+\frac{\psi\left(n_{3}\right)}{\left(n_{1}-n_{3}\right)\left(n_{2}-n_{3}\right)}=k \alpha^{39}
\end{aligned}
$$

If $a, b, c, d$, are the initial concentrations, the substitutions $n_{1} a=b$, $n_{2} a=c, n_{3} a=d, \lambda a=x, \vartheta=t$, reduce this to the form of integral given in the text-books.

\section{§3. The Case of Multiple Poles.}

When the initial concentrations of two or more reactants are equal, or when the number of molecules of any reactant exceeds unity, the corresponding integral could be obtained from a consideration of the appropriate limit in equation (11). This, though interesting mathematically, is hardly to be recommended as a practical method for chemists. It seems preferable to consider separately the different types according to the number of different concentrations involved in the integrand.

\section{(a) Single term denominator.}

This reduces to the comparatively trivial case of all initial concentrations being equal. If the reaction is $\mathrm{N}$-molecular the differential equation is

$$
\frac{d \lambda}{(1-\lambda)^{\mathrm{N}}}=k a^{\mathrm{N}-1} \cdot d \vartheta
$$

and the integral may be written

or

$$
(-1)^{\mathrm{N}-2} \frac{1}{\mathrm{~N}-2 !} \psi^{\mathrm{N}-2}(1)=a^{\mathrm{N}-1} k \vartheta
$$

$$
\frac{1}{\mathrm{~N}-1}\left[(1-\lambda)^{1-\mathrm{N}}-1\right]=a^{\mathrm{N}-1} k \vartheta
$$

which is obtainable by direct integration.

* The vanishing factor for $j=i$ is, of course, excluded from II. 
(b) Two-term denominator.

The type of integrand in this case is

It is resolved into

$$
\frac{1}{(1-\lambda)^{\alpha}(n-\lambda)^{\beta}} \text {. }
$$

where

$$
\sum_{1}^{a} \frac{\mathrm{A}_{r}}{(1-\lambda)^{r}}+\sum_{1}^{\beta} \frac{\mathrm{B}_{r}}{(n-\lambda)^{r}}
$$

$$
\begin{aligned}
& \mathrm{A}_{r}=(-1)^{\beta \beta+a-r-1} \mathrm{C}_{a-r} \frac{1}{(1-n)^{\beta+\alpha-r}} \\
& \mathrm{~B}_{r}=(-1)^{\alpha a+\beta-r-1} \mathrm{C}_{\beta-r} \frac{1}{(n-1)^{\alpha+\beta-r}}
\end{aligned}
$$

The C's are the usual binomial coefficients. Write $\alpha+\beta=\mathrm{N}$ (the total number of molecules involved), and the integral becomes

$$
\begin{aligned}
k a^{\mathrm{N}-1} \vartheta=(-1)^{\alpha} & \sum_{1}^{\alpha-1} \frac{1}{(n-1)^{\mathrm{N}-r-1}} \mathrm{~N}^{\mathrm{N}-r-2} \mathrm{C}_{\beta-1} \frac{\psi^{r-1}(1)}{r-1 !} \\
& +\sum_{1}^{\beta-1} \frac{(-1)^{r+\alpha}}{(n-1)^{\mathrm{N}-r-1}} \mathrm{~N}^{\mathrm{N}-r-2} \mathrm{C}_{\beta-r} \cdot \frac{\psi^{r-1}(n)}{r-1 !} \\
& +(-1)^{\mathrm{N}} \frac{1}{(n-1)^{\alpha-1}} \frac{\psi^{\beta-1}(n)}{\overline{\beta-1}} .
\end{aligned}
$$

This holds for $\alpha>1, \beta>1$. If $\alpha>2$ the last term in (18) may be dropped, and the second summation carried out between the limits 1 and $\beta$.

One can well imagine that the form of the solution (18) may not appeal to those for whom it is intended; but its generality will make it worth while mastering its symbols. It embraces, for instance, all the equations discussed by Todd,* which he integrates individually, and for which he gives individual curves.

As an example of the application of (18) consider the equation

$$
\frac{d x}{d t}=k(a-x)^{3}(b-x)
$$

Here $\alpha=3, \beta=1, \mathrm{~N}=4$. Substitution of these values in (18) gives

$$
k a^{3} \vartheta=\frac{1}{(n-1)^{2}}\left[-\psi(1)-(n-1) \psi^{\prime}(1)+\psi(n)\right]
$$

And for the equation

$$
\frac{d x}{d t}=k(a-x)^{2}(b-x)^{2}
$$

where $\alpha=2, \beta=2, \mathrm{~N}=4$, we get

$$
k a^{3} \vartheta=\frac{1}{(n-1)^{2}}\left[\psi(1)-\psi(n)+(n-1) \psi^{\prime}(n)\right]
$$

Substitution of the equivalents given in $\S 1$ leads to the ordinary algebraical solutions; while the use of the tables in $\S 5$ gives appropriate numerical results. 
It may be worth while pointing out some special simplifications of (18) that occur in practice.

$\alpha=1$ the two summations fall away, leaving

$$
k \alpha^{\beta \vartheta}=(-1)^{\beta-1} \frac{1}{\beta-1} \psi^{\beta-1}(n)
$$

If $\alpha=2$ the integral may be written

$$
\begin{aligned}
& k \alpha^{\beta+1 \vartheta}=\frac{1}{(n-1)^{\beta}}\left[\psi(1)-\psi(n)-(1-n) \psi^{\prime}(n)-\ldots-\right. \\
& \left.\frac{(1-n)^{\beta-1}}{\beta-1 !} \psi^{\beta-1}(n)\right] . \\
& \text { If } \beta=1 \text { we get } \\
& k \alpha^{\alpha} \vartheta=(-1)^{a+1} \frac{1}{(n-1)^{\alpha-1}\left[\psi(n)-\psi(1)-(n-1) \psi^{\prime}(1)-\ldots-\right.} . \\
& \left.\qquad \frac{(n-1)^{\alpha-2}}{a-2 !} \psi^{a-2}(1)\right] .
\end{aligned}
$$

\section{§4. The Determination of the Molecular Order.}

The results already given seem sufficient for the determination of molecular order with a minimum of experimental labour. Suppose, for instance, three reactants, A, B and C, are involved. The total number, N, of molecules, taking part may be determined in the usual way by performing two different experiments with all reactants in the same initial concentration, say $a_{1}$ and $a_{2}$. Then from (14),

$$
(-1)^{\mathrm{N}-2} \frac{\psi^{\mathrm{N}-2}(1)}{\mathrm{N}-2 !}=k a_{1}^{\mathrm{N}-1 \vartheta_{1}}=k a_{2}{ }^{\mathrm{N}-1 \vartheta_{2}} .
$$

The same fraction, $\lambda$, must be transformed in each case. These determine $\mathrm{N}$ and $k$. Now repeat the experiment with two concentrations, say those of $\mathrm{B}$ and $\mathrm{C}$, initially equal, and the other lower, the ratio being $n$. Suppose $\mathrm{N}$ has been found to be 5 . Of $\mathrm{A}$, either one, or two, or three molecules must be involved. The appropriate solutions would be

$$
\begin{aligned}
& k a^{4} \vartheta=-\frac{1}{3 !} \psi^{\prime \prime \prime}(n) \\
& k a^{4} \vartheta=\frac{1}{(n-1)^{3}}\left[\psi(1)-\psi(n)-(1-n) \psi^{\prime}(n)-\frac{(1-n)^{2}}{2 !} \psi^{\prime \prime}(n)\right]
\end{aligned}
$$

and

$$
k a^{4} \vartheta=\frac{1}{(n-1)^{3}}\left[2\{\psi(n)-\psi(1)\}-(n-1)\left\{\psi^{\prime}(1)+\psi^{\prime}(n)\right\}\right] .
$$

Knowing $k, a, \vartheta$ and $n$, a little arithmetic will show which of these equations is satisfied, and thus determine the molecular order of A. If purely chemical considerations do not fix the orders of $\mathrm{B}$ and $\mathrm{C}$, another reaction would have to be timed, using $\mathrm{A}$ and $\mathrm{C}$ in initially equal concentrations, and $\mathrm{B}$ lower. The same process would then give the molecular order of B. 


\section{$\S 5$. Numerical Values of $\psi, \psi^{\prime}, \psi^{\prime \prime}$.}

$\psi(n)$.

\begin{tabular}{|c|c|c|c|c|c|c|c|c|c|c|}
\hline \multicolumn{2}{|c|}{$\lambda=$} & $0 \cdot 1$ & $0 \cdot 2$ & 0.3 & 0.4 & 0.5 & $0^{\circ} 6$ & $0 \cdot 7$ & 0.8 & 0.9 \\
\hline \multirow{8}{*}{ हं } & 1 & $0 \cdot 11111$ & 0.25000 & 0.42857 & 0.66667 & 1.00000 & 1.50000 & $2 \cdot 33333$ & $4: 00000$ & $9 \cdot 00000$ \\
\hline & 2 & 0.05407 & $0 \cdot 11778$ & $0 \cdot 19416$ & 0.28768 & 0.40546 & 0.55962 & 0.77319 & $1 \cdot 09861$ & 1.70475 \\
\hline & 3 & 0.03573 & 0.07708 & $0 \cdot 12566$ & $0 \cdot 18386$ & 0.25541 & 0.34658 & 0.46914 & 0.64965 & 0.97291 \\
\hline & 4 & 0.02502 & 0.05728 & 0.09290 & 0.13515 & $0 \cdot 18654$ & 0.25126 & 0.33720 & 0.46210 & 0.68256 \\
\hline & 5 & $0 \cdot 02129$ & 0.04558 & 0.07370 & $0 \cdot 10686$ & $0 \cdot 14695$ & $0 \cdot 19711$ & 0.26329 & 0.35877 & 0.52603 \\
\hline & 6 & 001771 & 0.03785 & 0.06108 & 0.08837 & 0.12123 & $0 \cdot 16219$ & 0.21598 & 0.29327 & $0 \cdot 4.2801$ \\
\hline & 8 & 0.01325 & $0 \cdot 02826$ & 0.04549 & 0.06565 & $0 \cdot 08980$ & 0.11976 & $0 \cdot 15891$ & 0.21487 & $0 \cdot 31189$ \\
\hline & 10 & 0.01059 & 0.02254 & 0.03625 & 0.05222 & 007132 & 0.09494 & 0.12571 & $0 \cdot 16956$ & 0.24536 \\
\hline
\end{tabular}

$\psi^{\prime}(n)$

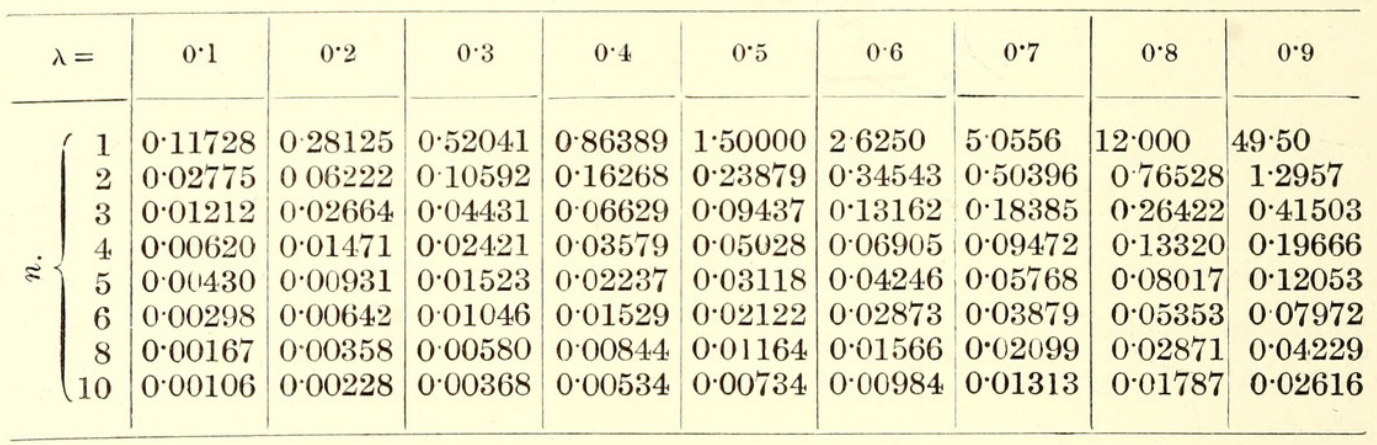

$$
\psi^{\prime \prime}(n) \text {. }
$$

\begin{tabular}{|c|c|c|c|c|c|c|c|c|c|}
\hline$\lambda=$ & $0 \cdot 1$ & $0 \cdot 2$ & 0.3 & $0 \cdot 4$ & 0.5 & 0.6 & $0 \cdot 7$ & 0.8 & 0.9 \\
\hline 1 & 0.24783 & $0 \cdot 63541$ & $1 \cdot 2770$ & $2 \cdot 4.197$ & $4: 6667$ & $9 \cdot 7500$ & $24: 025$ & $82 \cdot 667$ & $666^{\circ}$ \\
\hline 2 & 2849 & 0.06580 & $0 \cdot 11582$ & $0 \cdot 18473$ & 0.28314 & $0 \bullet 43066$ & $0 \cdot 66620$ & 1.08612 & $2 \cdot 01487$ \\
\hline 3 & 0.00822 & 0.01842 & 0.03128 & 004788 & 0.06993 & $0 \cdot 10037$ & $0 \cdot 14489$ & $0 \cdot 21647$ & 0.35721 \\
\hline 4 & 0.00305 & 0.00756 & 0.01262 & 0.01897 & 0.02714 & $0 \cdot 03803$ & 0.05337 & 0.07708 & $0 \cdot 11725$ \\
\hline 5 & 0.00174 & 0.00380 & 0.00630 & 0.00937 & 0.01324 & 0.01832 & 0.02532 & $0 \cdot 03591$ & 0.05539 \\
\hline 6 & 0.00100 & 0.00218 & 0.00358 & 0.00529 & 0.00743 & 0.01019 & 0.01395 & 0.01957 & 0.02975 \\
\hline 8 & 0.00042 & 0.0 & 0.00148 & 0.00217 & & & & 000768 & 0.01148 \\
\hline$(10$ & 0.00021 & 0.00046 & 0.00075 & 0.00109 & 0.00151 & 0.00204 & 0.00274 & 0.00377 & \begin{tabular}{l|l}
7 & 0.00558
\end{tabular} \\
\hline
\end{tabular}




\section{$2 \mathrm{BHL}$ Biodiversity Heritage Library}

Dalton, John P. 1921. "ON THE INTEGRATED VELOCITY EQUATIONS OF CHEMICAL REACTIONS." Transactions of the Royal Society of South Africa 9, 223-228. https://doi.org/10.1080/00359192109520216.

View This Item Online: https://www.biodiversitylibrary.org/item/181591

DOI: https://doi.org/10.1080/00359192109520216

Permalink: https://www.biodiversitylibrary.org/partpdf/175614

\section{Holding Institution}

Smithsonian Libraries

\section{Sponsored by}

Biodiversity Heritage Library

\section{Copyright \& Reuse}

Copyright Status: Not in copyright. The BHL knows of no copyright restrictions on this item.

This document was created from content at the Biodiversity Heritage Library, the world's largest open access digital library for biodiversity literature and archives. Visit BHL at https://www.biodiversitylibrary.org. 